\title{
Ginsenosides Inhibit HMGB1-induced Inflammatory Responses in HUVECs and in Murine Polymicrobial Sepsis
}

\author{
Wonhwa Lee, ${ }^{\dagger, a}$ Sae-Kwang Ku, ${ }^{\ddagger, a}$ Tae Cheon Jeong, ${ }^{\S}$ Sangkyu Lee, and Jong-Sup Bae* \\ College of Pharmacy, CMRI, Research Institute of Pharmaceutical Sciences, Kyungpook National University, \\ Daegu 702-701, Korea. E-mail: baejs@knu.ac.kr \\ †BK21 Plus KNU Biomedical Convergence Program, Department of Biochemistry and Cell Biology, School of Medicine, \\ Kyungpook National University, Daegu 700-422, Korea \\ Department of Anatomy and Histology, College of Korean Medicine, Daegu Haany University, Gyeongsan 712-715, Korea \\ ${ }^{\S}$ College of Pharmacy, Yeungnam University, Gyeongsan 712-749, Korea \\ Received March 27, 2014, Accepted June 10, 2014
}

\begin{abstract}
Asian ginseng is used as a treatment for cardiovascular diseases, ischemia, and cancers. High mobility group box 1 (HMGB1) protein acts as a late mediator of severe vascular inflammatory conditions. However, the effect of ginsenosides from Asian ginseng on HMGB1-induced inflammatory responses has not been studied. We addressed this question by monitoring the effects of ginsenoside treatment on lipopolysaccharide (LPS) and cecal ligation and puncture (CLP)-mediated release of HMGB1, and HMGB1-mediated regulation of proinflammatory responses. Ginsenoside treatment suppressed LPS-mediated release of HMGB1 and HMGB1mediated cytoskeletal rearrangements. Ginsenosides also inhibited HMGB1-mediated inflammatory responses. In addition, ginsenosides inhibited the production of tumor necrosis factor- $\alpha$ (TNF- $\alpha$ ) and activation of protein kinase $\mathrm{B}(\mathrm{Akt})$, nuclear factor- $\kappa \mathrm{B}(\mathrm{NF}-\kappa \mathrm{B})$, and extracellular-regulated kinases (ERK) $1 / 2$ by HMGB1. Ginsenosides also decreased CLP-induced release of HMGB1, production of interleukin (IL) 1 $\beta / 6$, and mortality. These results suggested that ginsenosides may be potential therapeutic agents for treatment of vascular inflammatory diseases through inhibition of the HMGB1 signaling pathway.
\end{abstract}

Key Words : Ginsenosides, HMGB1, Vascular inflammation, Sepsis

\section{Introduction}

Sepsis is a bacterial infection in the bloodstream or body tissues and is associated with a systemic inflammatory response to circulating bacterial products. Sepsis is potentially life threatening as it may progress to septic shock and multiple organ failure and is strongly correlated with unacceptably poor outcomes. ${ }^{1}$ International guidelines for the management of severe sepsis and septic shock recommend the use of both stress-dose steroid therapy and recombinant activated protein $\mathrm{C}$ (APC) in patients with septic shock. However, after the withdrawal of Xigris (APC; Eli Lilly, USA), there is a lack of pharmacological treatments; therefore, it is important to discover new sepsis treatments. ${ }^{2}$ Sepsis in vulnerable tissues is initiated upon recognition of bacterial components such as high mobility group box 1 (HMGB1), lipopolysaccharide (LPS), peptidoglycan, and lipoteichoic acid. ${ }^{3-5}$ One possible strategy is HMGB1-targeted therapeutics, which could be an effective method for the treatment of sepsis.

HMGB1 is both a nuclear factor and secreted protein. In the cell nucleus, it acts as an architectural chromatin-binding factor that bends DNA and promotes protein assembly on specific DNA targets. High concentration of HMGB1 in the plasma of patients with severe sepsis correlates with an

\footnotetext{
${ }^{\mathrm{a}}$ These authors contributed equally to this work.
}

increased likelihood of mortality. ${ }^{6}$ Outside the cell, HMGB1 binds with high affinity to the receptor for advanced glycation end products (RAGE) and toll-like receptors (TLR)-2 and TLR-4, and it is a potent mediator of inflammation. HMGB1 induces expression of cellular adhesion molecules on endothelial cells, such as vascular cell adhesion molecule-1 (VCAM-1), intercellular adhesion molecule-1 (ICAM-1), and E-selectin. ${ }^{7-10}$ Inflammatory responses in endothelial cells can be induced by HMGB1, which significantly enhances secretion of tumor necrosis factor (TNF) and interleukin 6 (IL-6), and can lead to increased phosphorylation of nuclear factor (NF)- $\kappa \mathrm{B}$ and extracellular-regulated kinases (ERK) 1 and $2 .^{10-12}$ Therefore, HMGB1 is a molecular target that provides an opportunity for clinical intervention in sepsis and perhaps other inflammatory diseases. ${ }^{8,13}$

Asian ginseng (Panax ginseng) is widely available as a health food product in the form of powders, capsules, tablets, soft gels, teas, or liquid extracts. Ginseng contains different ginsenosides, which are triterpenoidic saponins with the general structural formula shown in Figure $1 .{ }^{14}$ These can be classified into two groups as follows: protopanaxadiol (PD) group (Rb1, Rb2, Rc, and $\mathrm{Rd}$ ) and protopanaxatriol (PT) group (Rg1, Re, Rf, and Rg2). ${ }^{15}$ Ginseng has multiple pharmacological actions and has been used for the treatment of cardiovascular diseases, ischemia, and cancers as well as for improving overall stress tolerance ${ }^{16,17}$ and to promote healing of intractable skin ulcers in patients with diabetes 
mellitus. ${ }^{18}$ Ginsenoside Rb1 acted as a weak phytoestrogen in MCF-7 human breast cancer cells, ${ }^{19}$ and ginsenoside Rg1 attenuated the oxidative stress in the liver of exercised rats. ${ }^{20}$ Ginsenoside $\operatorname{Rg} 2$ prevented memory impairment by inhibiting apoptosis in a rat model of vascular dementia. ${ }^{21}$ To the best of our knowledge, the effects of ginsenosides on HMGB1-mediated inflammatory responses have not been studied yet. Our aim was to identify herbal compounds capable of modulating HMGB1-mediated inflammatory responses. In this study, we found that ginsenosides inhibited HMGB1-mediated inflammatory responses in both cell and animal models. Given that HMGB1 is a marker/target in vascular inflammatory disease and that it is involved in the pathophysiology of vascular inflammatory diseases, ${ }^{4,10,13,22-25}$ we hypothesized that ginsenosides might have anti-HMGB1 activities. Therefore, we investigated the effect of ginsenosides on HMGB1-mediated septic responses in human endothelial cells and in a cecal ligation and puncture (CLP) mouse model of septicemia.

\section{Experimental}

Reagents. Ginsenosides (Rb1, Rb2, Rc, Rd, Rf, and Rg1), bacterial lipopolysaccharide (LPS; serotype: 0111:B4, L5293), Evans blue, crystal violet, 2-mercaptoethanol, and antibiotics (penicillin $\mathrm{G}$ and streptomycin) were purchased from Sigma (St. Louis, MO, USA). Human recombinant HMGB1 was purchased from Abnova (Taipei City, Taiwan). Fetal bovine serum (FBS) and Vybrant DiD were purchased from Invitrogen (Carlsbad, CA, USA). Anti-HMGB1 neutralizing antibody was purchased from BioLegend (Tokyo, Japan)

Cell Culture. Primary human umbilical vein endothelial cells (HUVECs) were obtained from Cambrex Bio Science (Charles City, IA, USA) and maintained as described previously. ${ }^{26,27}$ Briefly, cells were cultured to confluency in EBM-2 basal media with growth supplements (Cambrex Bio Science) at $37^{\circ} \mathrm{C}$ in a humidified atmosphere containing $5 \%$ $\mathrm{CO}_{2}$. THP-1 cells, a monocyte cell line, were maintained as previously described. ${ }^{28}$

Animals and Husbandry. Male C57BL/6 mice (6-7 weeks, average weigh $20 \mathrm{~g}$ ) purchased from Orient Bio Co. (Sungnam, KyungKiDo, Republic of Korea) were used in this study after a 12-day acclimatization period. Animals were housed in polycarbonate cages ( 5 per cage) under controlled temperature $\left(20-25^{\circ} \mathrm{C}\right)$ and humidity $(40-45 \%)$ conditions and a $12 \mathrm{~h} / 12 \mathrm{~h}$ light/dark cycle. During acclimatization, animals were given a normal rodent pellet diet and water ad libitum. All animals were treated in accordance with the Guidelines for the Care and Use of Laboratory Animals issued by Kyungpook National University (KNU 2012-13).

Cell Viability Assay. 3-[4,5-Dimethylthiazol-2-yl]-2,5-diphenyltetrazolium bromide (MTT) was used as an indicator of cell viability. Cells were grown in 96-well plates at a density of $5 \times 10^{3}$ cells/well. After $24 \mathrm{~h}$, cells were washed with fresh medium, followed by treatment with each ginsenoside. After a 48-h incubation period, cells were washed and $100 \mu \mathrm{L}$ of MTT $(1 \mathrm{mg} / \mathrm{mL})$ were added followed by incubation for $4 \mathrm{~h}$. Finally, $150 \mu \mathrm{L}$ of dimethyl sulfoxide (DMSO) was added in order to solubilize the formazan salt formed, and the amount of formazan salt was determined by measuring the absorbance at $540 \mathrm{~nm}$ using a microplate reader (Tecan Austria GmbH, Austria).

Competitive Enzyme-linked Immunosorbent Assay (ELISA) for HMGB1. The concentration of HMGB1 was determined by using the competitive ELISA method as previously described. ${ }^{29}$ Briefly, 96-well flat plastic microtiter plates (Corning, NY, USA) were coated with HMGB1 protein in $20 \mathrm{mM}$ carbonate bicarbonate buffer ( $\mathrm{pH} 9.6$ ), containing $0.02 \%$ sodium azide, overnight at $4{ }^{\circ} \mathrm{C}$. Then, plates were rinsed three times with phosphate-buffered saline (PBS), containing $0.05 \%$ Tween 20 , (PBST) and kept at $4{ }^{\circ} \mathrm{C}$. Lyophilized culture media were pre-incubated with antiHMGB1 antibodies diluted 1:1,000 in PBST in 96-well plastic round microtiter plates for $90 \mathrm{~min}$ at $37^{\circ} \mathrm{C}$. Next, the pre-incubated samples were transferred to pre-coated plates and incubated for $30 \mathrm{~min}$ at room temperature. Plates were then rinsed three times with PBST, incubated for $90 \mathrm{~min}$ at room temperature with peroxidase-conjugated anti-rabbit IgG antibodies (Amersham Pharmacia Biotech, Sweden) diluted 1:2,000 in PBST, rinsed three times with PBST, and incubated for $60 \mathrm{~min}$ at room temperature in the dark with $200 \mu \mathrm{L}$ of substrate solution $(100 \mu \mathrm{g} / \mathrm{mL} o$-phenylenediamine and $0.003 \% \mathrm{H}_{2} \mathrm{O}_{2}$ ). The absorbance at $490 \mathrm{~nm}$ was measured after stopping the reaction with $50 \mu \mathrm{L}$ of $8 \mathrm{~N} \mathrm{H}_{2} \mathrm{SO}_{4}$.

Expression of Cell Adhesion Molecules and Receptors. Expression of VCAM-1, ICAM-1, and E-selectin in HUVECs was determined by using a whole-cell ELISA as previously described. $^{30,31}$ Briefly, confluent monolayers of HUVECs were treated with HMGB1 $(1 \mu \mathrm{g} / \mathrm{mL})$ for $16 \mathrm{~h}$ followed by treatment with each ginsenoside for $6 \mathrm{~h}$. The medium was removed, and cells were washed with PBS and fixed with 50 $\mu \mathrm{L}$ of $1 \%$ paraformaldehyde for $15 \mathrm{~min}$ at room temperature. After washing, the cells were incubated with $100 \mu \mathrm{L}$ of mouse anti-human VCAM-1, ICAM-1, and E-selectin monoclonal antibodies (1:50, Temecula, CA, USA) for $1 \mathrm{~h}$ at $37^{\circ} \mathrm{C}$. Next, the cells were washed three times followed by addition of $100 \mu \mathrm{L}$ of peroxidase-conjugated anti-mouse IgG antibodies (1:2,000; Sigma, Saint Louis, MO) for $1 \mathrm{~h}$. The cells were washed again three times and $o$-phenylenediamene substrate (Sigma, St. Louis, MO) was added. Colorimetric analysis was performed by measuring the absorbance at $490 \mathrm{~nm}$. All measurements were performed in triplicate.

The same experimental procedures were used for monitoring the cell surface expression of TLR2, TLR4, and RAGE receptors by using specific antibodies (A-9, H-80, and A-9, respectively) obtained from Santa Cruz Biotechnology Inc. (Santa Cruz, CA).

ELISA for Phosphorylated p38 Mitogen-activated Protein Kinase (MAPK). Expression of phosphorylated p38 MAPK was quantified using a commercially available ELISA kit (Cell Signaling Technology, Danvers, MA, USA) according to the manufacturer's instructions

Permeability Assay in vitro. Endothelial cell permeability 
in response to increasing concentrations of each ginsenoside was quantified by measuring the flux of Evans blue-bound albumin across functional cell monolayers by using a modified two-compartment chamber model, as previously described. ${ }^{32}$ HUVECs were plated at $5 \times 10^{4}$ cells/well in 3 $\mu \mathrm{m}$ pore size, $12-\mathrm{mm}$ diameter transwells and cultured for three days. Confluent monolayers of HUVECs were treated with HMGB1 $(1 \mu \mathrm{g} / \mathrm{mL})$ for $16 \mathrm{~h}$ followed by treatment with each ginsenoside for $6 \mathrm{~h}$. Then, transwell inserts were washed with PBS ( $\mathrm{pH} 7.4$ ) followed by addition of $0.5 \mathrm{~mL}$ of Evans blue $(0.67 \mathrm{mg} / \mathrm{mL})$ diluted in growth medium containing $4 \%$ bovine serum albumin (BSA). Fresh growth medium was then added to the lower chamber, and the medium in the upper chamber was replaced with Evans blue/ BSA. Ten minutes later, the optical density of the contents of the lower chamber was measured at $650 \mathrm{~nm}$.

Migration Assay in vitro. Migration assays were performed in $6.5 \mathrm{~mm}$ diameter transwell plates containing $8-\mu \mathrm{m}$ pore size filters. HUVECs $\left(6 \times 10^{4}\right.$ cells $)$ were cultured for three days in order to obtain confluent endothelial monolayers. Before addition of THP-1 cells to the upper compartment, cell monolayers were treated with HMGB1 $(1 \mu \mathrm{g} / \mathrm{mL})$ for $16 \mathrm{~h}$ followed by treatment with each ginsenoside for $6 \mathrm{~h}$. Then, transwell plates were incubated at $37^{\circ} \mathrm{C}$ for $2 \mathrm{~h}$. Cells in the upper chamber were then aspirated and non-migrating cells on top of the filter were removed using a cotton swab. THP-1 cells on the lower side of the filter were fixed with $8 \%$ glutaraldehyde and stained with $0.25 \%$ crystal violet dissolved in $20 \%$ methanol $(\mathrm{w} / \mathrm{v})$. Each experiment was repeated twice with duplicate wells per treatment, the cells in nine randomly selected high power microscopic fields $(200 \times)$ were counted, and the results were expressed as Migration Indices.

In vivo Permeability and Leukocyte Migration Assays. Male mice were anesthetized with zoletil (tiletamine and zolazepam, 1:1 mixture, $30 \mathrm{mg} / \mathrm{kg}$ ) and rompun (xylazine, $10 \mathrm{mg} / \mathrm{kg}$ ). Mice, which had undergone CLP, or control were treated with HMGB1 ( $2 \mu \mathrm{g} /$ mouse) intravenously (i.v.), and $16 \mathrm{~h}$ later each ginsenoside was injected intravenously. After $6 \mathrm{~h}, 1 \%$ Evans blue dye solution in normal saline was administered intravenously to each mouse. Thirty minutes later, the mice were sacrificed and the peritoneal exudates were collected after washing with $5 \mathrm{~mL}$ normal saline and centrifuged at $200 \times \mathrm{g}$ for $10 \mathrm{~min}$. The absorbance of the supernatant was measured at $650 \mathrm{~nm}$. Vascular permeability was expressed as the amount of dye ( $\mu \mathrm{g} /$ mouse), which had leaked into the peritoneal cavity according to a standard curve of Evans blue dye as previously described. ${ }^{33,34}$

For assessment of leukocyte and neutrophil migration, mice, which had undergone CLP, or control mice were intravenously administered HMGB1 $(2 \mu \mathrm{g} /$ mouse $)$ in normal saline. After $16 \mathrm{~h}$, mice were treated with each ginsenoside for $6 \mathrm{~h}$. The mice were then sacrificed and the peritoneal cavities were washed with $5 \mathrm{~mL}$ of normal saline. Twenty microliters of peritoneal fluid was mixed with $0.38 \mathrm{~mL}$ of Turk's solution $(0.01 \%$ crystal violet in $3 \%$ acetic acid), and the number of leukocytes was counted under a light micro- scope. To determine neutrophil migration to the peritoneal cavity, total cell counts were performed using a cell counter (Coulter AC T series analyzer; Coulter Corporation, Miami, Florida, USA) and differential cell counts were carried out on cytocentrifuge slides (Cytospin 3; Shandon Southern Products, Astmoore, UK) stained by the May-GrümwaldGiemsa (Rosenfeld) method. ${ }^{35}$ The results were expressed as the number of neutrophils $\times 10^{6}$ per peritoneal cavity.

Cell-Cell Adhesion Assay. THP-1 cell adhesion to HUVECs was evaluated fluorescent labeling of THP-1 cells as previously described. ${ }^{36}$ Briefly, THP- 1 cells $\left(1.5 \times 10^{6} / \mathrm{mL}, 200\right.$ $\mu \mathrm{L} /$ well) were labeled with Vybrant DiD dye and then added to washed and stimulated HUVECs. HUVEC monolayers were treated with HMGB1 $(1 \mu \mathrm{g} / \mathrm{mL})$ for $16 \mathrm{~h}$, followed by treatment with each ginsenoside for $6 \mathrm{~h}$. THP-1 cells were allowed to adhere and non-adherent THP-1 cells were removed by washing. The percentage of adherent THP-1 cells was calculated by using the formula: $\%$ adhesion $=($ adherent signal/total signal $) \times 100$. Results are expressed as the mean of the least three independent experiments.

ELISA for NF- $\kappa$ B, ERK1/2, TNF- $\alpha$, IL-1 $\beta$, IL-6 and keratinocyte chemoattractant $(\mathrm{KC}$; functional homolog to human IL-8). Total and phosphorylated p65 NF- $\kappa \mathrm{B}$ (\#7174 and \#7173, respectively) and total and phosphorylated Akt (\#7170 and \#7252, respectively) ELISA kits from Cell Signaling Technology (Danvers, MA, USA), and total and phosphorylated ERK1/2 ELISA kits from R\&D Systems (Minneapolis, MN, USA) were used to determine the levels of the indicated proteins in nuclear lysates. The concentrations of TNF- $\alpha$ in cell culture supernatants and IL-1 $\beta$, IL6 , and $\mathrm{KC}$ in mouse plasma were determined by using ELISA kits (R\&D Systems, Minneapolis, MN, USA). Values were measured by using an ELISA plate reader (Tecan, Austria $\mathrm{GmbH}$, Austria).

Immunofluorescence Staining. HUVECs were plated on glass cover slips coated with $0.05 \%$ poly-L-Lysine in complete medium containing 10\% FBS and cultured for 48 h. Confluent cultures were then stimulated with LPS (100 $\mathrm{ng} / \mathrm{mL})$ or HMGB1 $(1 \mu \mathrm{g} / \mathrm{mL})$ for $1 \mathrm{~h}$ with or without treatment with $10 \mu \mathrm{M}$ of each ginsenoside for $1 \mathrm{~h}$. For cytoskeletal staining, cells were fixed in $4 \%$ formaldehyde in PBS (v/v) for $15 \mathrm{~min}$ at room temperature, and for immunostaining, cells were additionally permeabilized in $0.05 \%$ Triton X-100 in PBS for $15 \mathrm{~min}$, and incubated in blocking buffer $\left(5 \%\right.$ BSA in PBS) overnight at $4{ }^{\circ} \mathrm{C}$. Cells were incubated with fluorescein-labeled phalloidin (F 432; Molecular Probes, Invitrogen) overnight at $4{ }^{\circ} \mathrm{C}$. Cells were visualized by confocal microscopy at $630 \times$ magnification (TCS-Sp5, Leica microsystem, Germany).

Cecal Ligation and Puncture (CLP). Male mice were anesthetized with zoletil (tiletamine and zolazepam, 1:1 mixture, $30 \mathrm{mg} / \mathrm{kg}$ ) and rompun (xylazine, $10 \mathrm{mg} / \mathrm{kg}$ ). The CLP procedure was performed as described previously. ${ }^{37} \mathrm{In}$ brief, a $2-\mathrm{cm}$ midline incision was made to expose the cecum and adjoining intestine. The cecum was then tightly ligated $5.0 \mathrm{~mm}$ from the cecal tip by using a 3.0 -silk suture, and it was punctured once by using a 22-gauge needle. The cecum 
was then gently squeezed in order to extrude a small amount of feces from the perforation site and returned to the peritoneal cavity. The laparotomy site was then sutured with a 4.0-silk suture. In sham control animals, the cecum was exposed but not ligated or punctured and then returned to the abdominal cavity. This protocol was approved by the Animal Care Committee at Kyungpook National University.

Statistical Analysis. Results are expressed as the mean \pm standard error of mean (SEM) of at least three independent experiments. Statistical significance was determined by using analysis of variance (ANOVA; SPSS, version 14.0, SPSS Science, Chicago, Il, USA) and p-values less than 0.05 $(p<0.05)$ were considered significant.

\section{Results and Discussion}

Ginsenosides are generally classified into two main categories based on the attachment position of different watersoluble sugar moieties to the non-polar aglycone. The amphiphilic nature ginsenosides is influenced by the polarity of the different sugar moieties attached to the ring structure. The different combinations of sugar moieties are attached at position C-3 of the PD dammarane ring structure, while PT has two attachment sites at positions C-3 and C-6. The PD type includes common ginsenosides, such as Rb1, Rb2, Rc, and $\mathrm{Rd}$, and rarer types, such as $\mathrm{Rg} 3$ and $\mathrm{Rh} 2$, while the PT type includes Re, Rf, Rg1, Rg2, and Rh1. In this study, the effects of each ginsenoside (Fig. 1) on HMGB1 release and HMGB1-mediated vascular barrier disruption were determined in vitro and in vivo.

Effect of Ginsenosides on LPS- and CLP-mediated Release of HMGB1. Previous studies have demonstrated that LPS stimulates the release of HMGB1 in murine macrophages and human endothelial cells. ${ }^{32,38,39}$ In agreement with the previous results, LPS $(100 \mathrm{ng} / \mathrm{mL})$ stimulated the release of HMGB1 by HUVECs (Fig. 2(a)). To investigate the effects of ginsenosides on LPS-mediated release of HMGB1, endothelial cells were stimulated with $100 \mathrm{ng} / \mathrm{mL}$ LPS for $16 \mathrm{~h}$ before treatment with increasing concentrations of each ginsenoside for $6 \mathrm{~h}$. The results shown in Figures 2(a) and

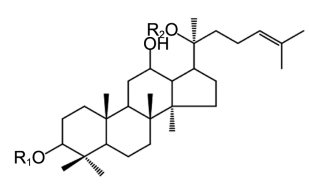

\begin{tabular}{lll|ccc}
\hline \multirow{2}{*}{} & \multirow{2}{*}{ R1 } & \multirow{2}{*}{$\mathrm{R} 2$} & \multicolumn{3}{|c}{$\begin{array}{c}\text { Amounts in vivo } \\
(\mu \mathrm{g} / \mathrm{mouse})\end{array}$} \\
\cline { 4 - 6 } & & $1 \mu \mathrm{M}$ & $5 \mu \mathrm{M}$ & $10 \mu \mathrm{M}$ \\
\hline Rb1 & O-G-G & O-G-G & 2.2 & 11.1 & 22.2 \\
Rb2 & O-G-G & O-G-Ap & 2.2 & 10.8 & 21.6 \\
Rc & O-G-G & O-G-Af & 2.2 & 10.8 & 21.6 \\
Rd & O-G-G & O-G & 1.9 & 9.5 & 18.9 \\
\hline
\end{tabular}

20 (S) Protopanaxadiol (PD)

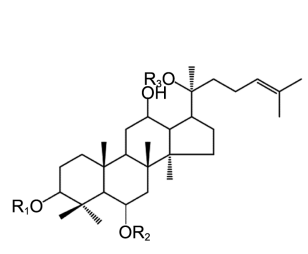

Ap; arabinopyranose Af; arabinofuranose G; glucopyranose

20 (S) Protopanaxatriol (PT)

\begin{tabular}{llll|ccc}
\hline & \multirow{2}{*}{ R1 } & \multirow{2}{*}{ R2 } & \multirow{2}{*}{ R3 } & \multicolumn{3}{|c}{$\begin{array}{c}\text { Amounts in vivo } \\
(\mu \mathrm{g} / \text { mouse })\end{array}$} \\
\cline { 4 - 6 } & & & $1 \mu \mathrm{M}$ & $5 \mu \mathrm{M}$ & $10 \mu \mathrm{M}$ \\
\hline Rf & O-H & O-G-G & O-H & 2.2 & 11.1 & 22.2 \\
Rg1 & O-H & O-G & O-G & 2.2 & 10.8 & 21.6 \\
\hline
\end{tabular}

Figure 1. Chemical structures of ginsenosides classified as (a) protopanaxadiol and (b) protopanazatriol groups. The amounts of ginsenosides used for the in vivo study are also shown. (b) indicated that each ginsenoside inhibited HMGB1 release by LPS-stimulated endothelial cells, with the optimal effect occurring at concentrations exceeding $2 \mu \mathrm{M}$. However, ginsenoside treatment alone did not affect HMGB1 release (Fig. 2(a) and (b)). To confirm this effect in vivo, we induced severe sepsis in mice by using a standardized model of CLP since this model closely resembles human sepsis. ${ }^{40}$ As shown in Figure 2(c) and (d), each ginsenoside markedly inhibited CLP-induced HMGB1 release in mice. Since the average weight of a mouse is $20 \mathrm{~g}$ and the average blood volume is 2 $\mathrm{mL}$, each injected ginsenoside (Fig. 1) had a concentration maximum of 1,2 , or $10 \mu \mathrm{M}$ in peripheral blood. Next, we investigated the effects of ginsenosides on the expression of the HMGB1 receptors TLR2, TLR4, and RAGE in HUVECs. As shown in Figure 2(e), HMGB1 increased expression of
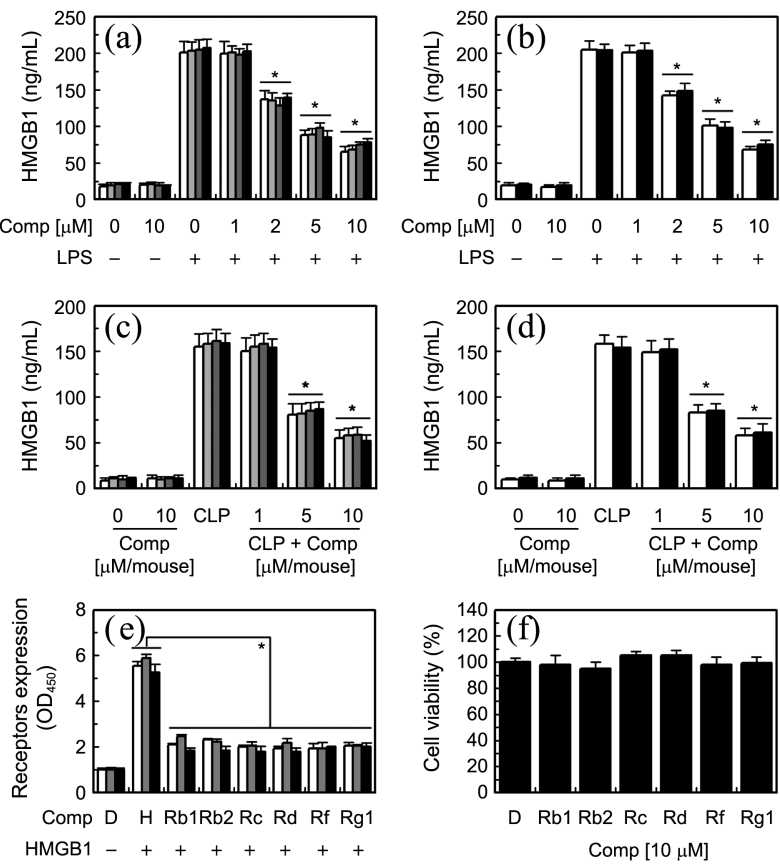

Figure 2. Effects of ginsenosides on HMGB1 release and receptor expression. (a) HUVECs were treated with the indicated concentrations of $\mathrm{Rb} 1$ (white bars), $\mathrm{Rb} 2$ (light gray bars), Rc (dark gray bars), or Rd (black bars) for $6 \mathrm{~h}$ after stimulation with $100 \mathrm{ng} / \mathrm{mL}$ of LPS for $16 \mathrm{~h}$. HMGB1 release was measured by using an ELISA. ( $b$ and d) The treatments were the same as in (a) except that cells were treated with $\mathrm{Rf}$ (white bars) or $\mathrm{Rg} 1$ (black bars). (c) Male C57BL/6 mice were administered Rb1 (white bars), Rb2 (light gray bars), Rc (dark gray bars), or Rd (black bars) intravenously $12 \mathrm{~h}$ after CLP $(\mathrm{n}=5)$. Mice were euthanized $24 \mathrm{~h}$ after CLP. Serum HMGB1 levels were measured by using an ELISA. (d) The experimental setup was the same as in (c) except that mice were administered Rf (white bars) or Rg1 (black bars). (e) Confluent HUVECs were incubated with HMGB1 $(1 \mu \mathrm{g} / \mathrm{mL})$ for $16 \mathrm{~h}$ and were then cultured with or without $10 \mu \mathrm{M}$ of each ginsenoside for $6 \mathrm{~h}$. Expression of TLR-2 (white bars), TLR-4 (gray bars), and RAGE (black bars) on HUVECs was measured by using a cellbased ELISA. D and $\mathbf{H}$ indicate treatment with $0.5 \%$ DMSO or HMGB1, respectively. (f) The effects of each ginsenoside on cell viability were measured by using MTT assays. Results are expressed as the mean \pm SEM of three independent experiments. * indicates $p<0.05$ versus LPS alone (a, b), CLP (c, e), or HMGB1 alone (e). 
TLR-2, TLR-4, and RAGE in HUVECs over 5-fold, and treatment with each ginsenoside resulted in marked inhibition of receptor expression. To exclude the possibility that the inhibition of HMGB1 release was due to ginsenosideinduced cytotoxicity, cell viability assays were performed with HUVECs treated with each ginsenoside for $24 \mathrm{~h}$. None of the ginsenosides affected cell viability at concentrations up to $10 \mu \mathrm{M}$ (Fig. 2(f)). High plasma HMGB1 concentrations in patients with inflammatory diseases are associated with a poor prognosis and high mortality. In addition, the pharmacological inhibition of HMGB1 is known to improve survival in animal models of acute inflammation in response to endotoxin challenge. ${ }^{41}$ Therefore, the prevention of LPSor CLP-induced release of HMGB1 by ginsenosides suggested that they may be used for the treatment of vascular inflammatory diseases.

Effect of Ginsenosides on LPS- or HMGB1-mediated Barrier Disruption. A permeability assay was performed to determine the effects of ginsenosides on endothelial cell barrier integrity.

Treatment with each ginsenoside $(10 \mu \mathrm{M})$ alone did not result in alterations in endothelial cell barrier integrity (data not shown). However, LPS is known to induce cleavage and disruption of endothelial membrane barriers. ${ }^{42,43}$ HUVECs were treated with different concentrations of ginsenosides for $6 \mathrm{~h}$ after addition of LPS (100 ng/mL). As shown in Fig $3 \mathrm{~A}$, each ginsenoside inhibited LPS-mediated membrane disruption in a dose-dependent manner. HMGB1 is also known to disrupt endothelial cell barrier integrity. ${ }^{25,44}$ Therefore, HUVECs were treated with different concentrations of ginsenosides for $6 \mathrm{~h}$ after addition of HMGB1 $(1 \mu \mathrm{g} / \mathrm{mL})$. As shown in Figure 3(b), treatment with each ginsenoside decreased HMGB1-mediated membrane disruption in a dosedependent manner. To confirm this effect in vivo, HMGB1or CLP-induced vascular permeability in mice was evaluated. As shown in Figure 3(c), each ginsenoside markedly inhibited the peritoneal leakage of dye induced by HMGB1 or CLP.

HMGB1 is known to induce pro-inflammatory responses by promoting phosphorylation of p38 MAPK. ${ }^{45,46}$ To examine whether ginsenosides could inhibit HMGB1-induced activation of p38 MAPK in HUVECs, cells were activated with HMGB1 and then incubated with each ginsenoside, followed by determination of phosphorylated p38 MAPK levels. As shown in Figure 3(d), HMGB1 up-regulated the expression of phosphorylated p38 and each of the tested ginsenosides significantly inhibited this effect. These findings demonstrated that ginsenosides could inhibit HMGB1mediated human endothelial cell barrier disruption and maintain endothelial cell barrier integrity in mice treated with HMGB1.

Cytoskeletal proteins are important for maintenance of cell integrity and shape..$^{47}$ In addition, redistribution of the actin cytoskeleton, cell detachment, and loss of cell-cell contact due to cytokine stimulation are all associated with increased endothelial monolayer permeability. ${ }^{48,49}$ Therefore, we examined the effects of ginsenosides on HUVEC actin cytoskeletal arrangement by immunofluorescence
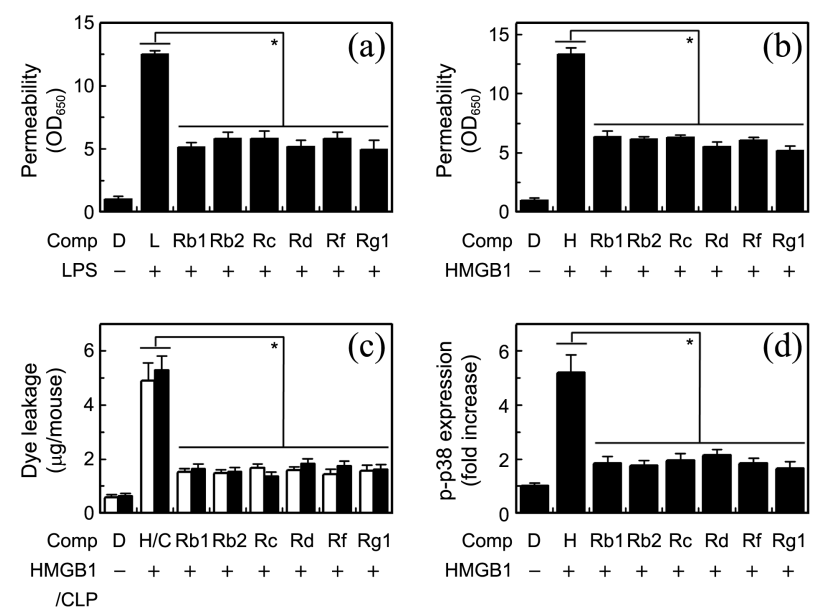

E

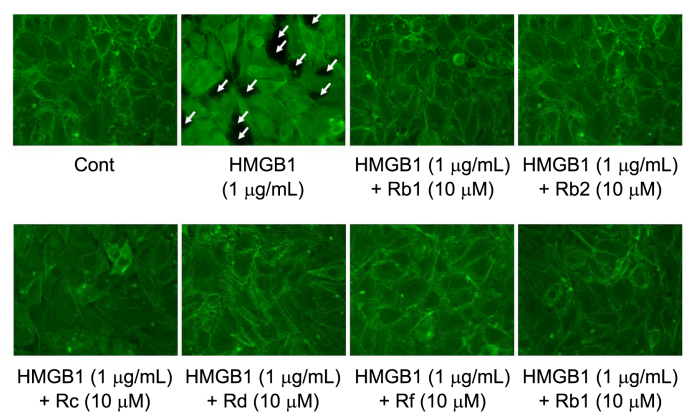

Figure 3. Effects of ginsenosides on HMGB1-induced permeability in vitro and in vivo. (a) HUVECs were stimulated with LPS (100 $\mathrm{ng} / \mathrm{mL}$ for $4 \mathrm{~h})$ or (b) HMGB1 $(1 \mu \mathrm{g} / \mathrm{mL}$ for $16 \mathrm{~h})$ and then treated with $10 \mu \mathrm{M}$ of each ginsenoside for $6 \mathrm{~h}$. Permeability was monitored by measuring the flux of Evans blue-bound albumin across HUVEC monolayers. (c) The effects of intravenously (i.v.) injected ginsenosides $(10 \mu \mathrm{M} /$ mouse $)$ on HMGB1- $(2 \mu \mathrm{g} /$ mouse, i.v., white bars) or CLP- (black bars) induced vascular permeability in mice were examined by measuring the amount of Evans blue in peritoneal washings (expressed in $\mu \mathrm{g} /$ mouse, $\mathrm{n}=5$ ). $\mathbf{H}$ and C indicate treatment with HMGB1 or CLP, respectively. (d) HUVECs were activated with HMGB1 and were then treated with $10 \mu \mathrm{M}$ of each ginsenoside for $6 \mathrm{~h}$. The effects of ginsenosides on HMGB1-mediated expression of phospho-p38 were measured by ELISA. (e) HUVEC monolayers grown on glass cover slips were stimulated with HMGB1 for $1 \mathrm{~h}$ followed by treatment with 10 $\mu \mathrm{M}$ of each ginsenoside for $6 \mathrm{~h}$, and immunofluorescence staining for F-actin. Arrows indicate intercellular gaps. Results are expressed as the mean \pm SEM of three independent experiments. ${ }^{*} p<0.05$ versus LPS (a), HMGB1 (b, c, d), or CLP (c).

staining of HUVEC monolayers with fluorescein-labeled phalloidin. F-actin was distributed randomly in control HUVECs with some localization of actin filament bundles at cell boundaries (Fig. 3(e)). Barrier disruption by HMGB1 (1 $\mu \mathrm{g} / \mathrm{mL}$ ) was manifested in the formation of paracellular gaps (indicated by arrows) in HUVEC cultures. Similar cytoskeletal rearrangements were induced by $100 \mathrm{ng} / \mathrm{mL}$ of LPS (data not shown). However, treatment with each ginsenoside $(10 \mu \mathrm{M})$ inhibited the formation of HMGB1-induced paracellular gaps while resulting in formation of dense F-actin rings (Fig. 3(e)). These results suggested that ginsenoside treatment inhibited HMGB1-mediated morphological changes and gap formation in endothelial cell cultures associated with $\mathrm{F}$-actin redistribution, thereby increasing vascular barrier 
integrity.

Ginsenosides Inhibit the Expression of CAMs and Proinflammatory Responses. Previous studies have demonstrated that HMGB1 mediates inflammatory responses by increasing the cell surface expression of cell adhesion molecules, such as ICAM-1, VCAM-1, and E-selectin on endothelial cells, thereby promoting adhesion and migration of leukocytes across the endothelium to sites of inflammation. ${ }^{7}$ To determine the effects of ginsenosides on expression of CAMs in HMGB1-stimulated endothelial cells, we monitored expression of VCAM-1, ICAM-1, and E-selectin in HMGB1-stimulated cells. As shown in Figure 4(a), each ginsenoside suppressed the expression of VCAM-1, ICAM1, and E-selectin. Adhesion of leukocytes to endothelial cells and transendothelial migration (TEM) of leukocytes are important steps in the proinflammatory response. ${ }^{50}$ Therefore, we attempted to determine whether expression of CAMs corresponded to enhanced leukocyte binding, and whether ginsenosides could block adhesion of monocytes to HMGB1stimulated HUVECs. We found that each ginsenoside effectively inhibited binding of leukocytes to HMGB1-stimulated HUVECs (Fig. 4(b)). Further studies revealed an association between leukocyte binding to HUVECs and the subsequent TEM of leukocytes, and that each ginsenoside could effectively inhibit this step (Fig. 4(c)). To confirm this effect in vivo, HMGB1- or CLP-induced leukocyte migration was examined in mice. HMGB1 and CLP induced significant migration of leukocytes into the peritoneal cavities of mice,
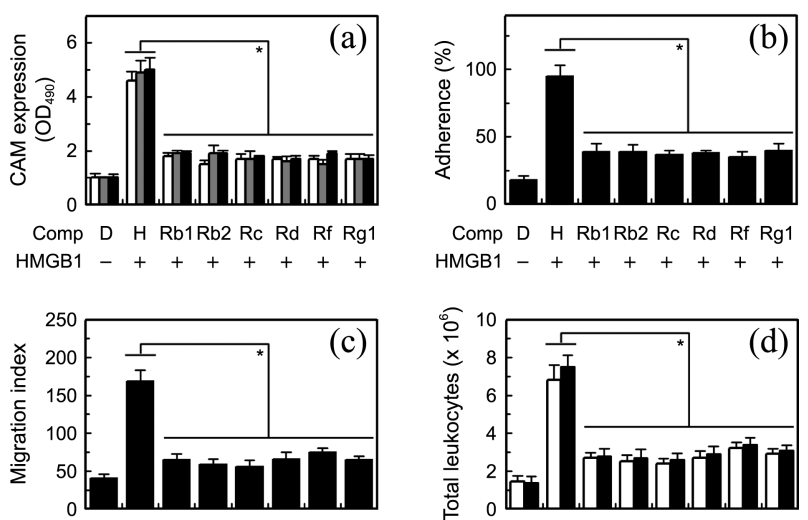

Comp D H Rb1Rb2 Rc Rd Rf Rg1 HMGB1 -++++++

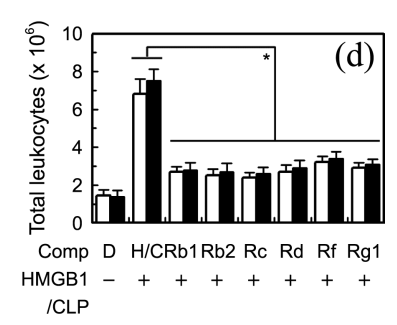

Figure 4. Effect of ginsenosides on HMGB1-mediated proinflammatory responses. HUVECs were stimulated with HMGB1 $(1 \mu \mathrm{g} / \mathrm{mL})$ for $16 \mathrm{~h}$ followed by treatment with $10 \mu \mathrm{M}$ of each ginsenoside for $6 \mathrm{~h}$. HMGB1-mediated expression of VCAM-1 (white bars), ICAM-1 (gray bars), and E-selectin (black bars) in HUVECs (A), adherence of monocytes to HUVEC monolayers (b), and migration of monocytes through HUVEC monolayers (c) were analyzed. (d) Male C57BL/6 mice stimulated with HMGB1 ( $2 \mu \mathrm{g} /$ mouse, i.v., white bars) or mice with CLP (black bars) were treated with $10 \mu \mathrm{M}$ of each ginsenoside. HMGB1- or CLPinduced migration of leukocytes into the peritoneal cavity of mice was analyzed. $\mathbf{H}$ and $\mathbf{C}$ indicate treatment with HMGB1 or CLP, respectively. Results are expressed as the mean \pm SEM of three independent experiments. $*$ indicates $p<0.05 v s$. HMGB1 (a-d) or CLP (d).

and each ginsenoside significantly inhibited this process (Fig. 4(d)). These results indicated that ginsenosides not only inhibited the endotoxin-mediated release of HMGB1 by endothelial cells, but that they also downregulated the pro-inflammatory effect of released HMGB1, and thereby inhibited the amplification of inflammatory responses such as the upregulation of CAMs, and leukocyte adhesion and migration by HMGB1.

Ginsenosides Inhibit the HMGB1-induced Activation of NF- $\kappa \mathrm{B}, \mathrm{ERK}$, and Akt and Production of TNF- $\alpha$ and IL-1 $\beta$. Both HMGB1 and LPS induced a significant increase in nuclear translocation of $\mathrm{NF}-\kappa \mathrm{B}$ and phosphorylation of Akt and p38 MAPK in human endothelial cells. ${ }^{13,51-53}$ Furthermore, activation of NF-kB and ERK1/2 was required for pro-inflammatory responses. ${ }^{54-56}$ Previous studies have reported activation of NF- $\kappa$ B and ERK $1 / 2$ by HMGB1 in vascular inflammatory responses. ${ }^{24,57,58}$ Therefore, to investigate the effects of ginsenosides on activation of inflammatory signaling molecules and production of TNF- $\alpha$ and IL-1 $\beta$ in HMGB1-activated HUVECs, cells were activated with HMGB1 for $16 \mathrm{~h}$ followed by incubation with each ginsenoside for $6 \mathrm{~h}$. The results showed that ginsenosides inhibited the HMGB1-mediated increase in NF- $\kappa B$ (Fig. 5(a)), ERK1/2 (Fig. 5(b)), and Akt (Fig. 5(c)) phosphorylation, and TNF- $\alpha$ (Fig. 5(d)) and IL-1 $\beta$ (Fig. 5(e)) production. This suggested that each of the tested ginsenosides
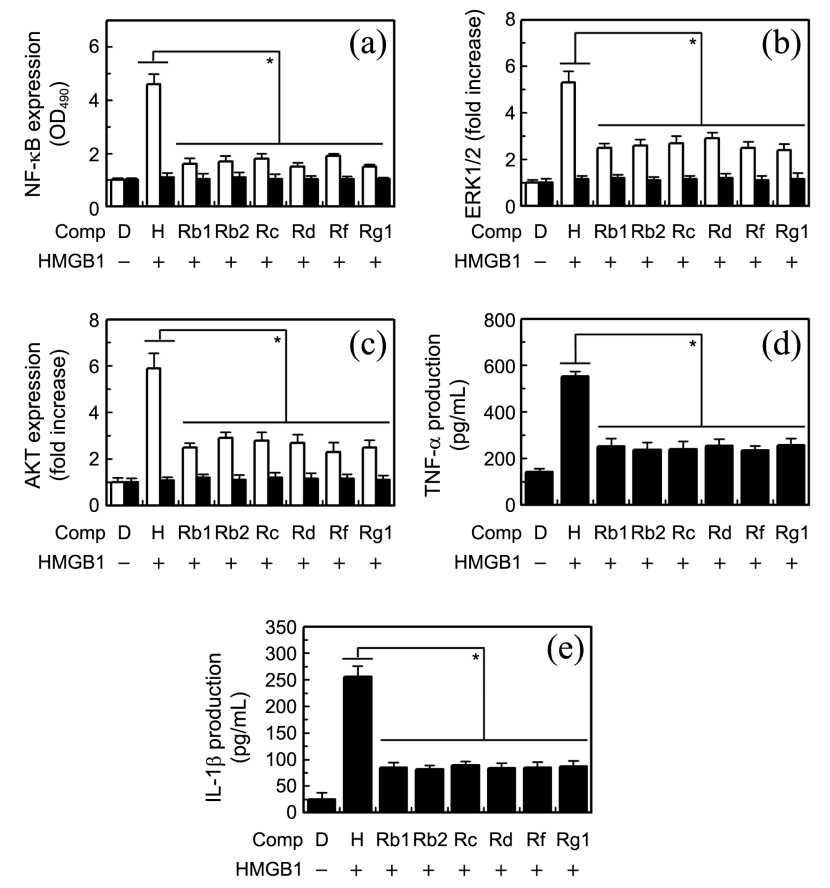

Figure 5. Effects of ginsenosides on HMGB1-induced activation of NF- $\mathrm{KB}, \mathrm{ERK}$, and Akt and production of TNF- $\alpha / \mathrm{IL}-1 \beta$ in HUVECs. HUVECs were stimulated with HMGB1 $(1 \mu \mathrm{g} / \mathrm{mL})$ for $16 \mathrm{~h}$ followed by treatment with $10 \mu \mathrm{M}$ of each ginsenoside for $6 \mathrm{~h}$. (a) NF- $\mathrm{kB}$ p65, (b) ERK1/2, and (c) Akt expression in HUVECs was analyzed (the white and black bars indicate phosphorylated and total protein, respectively). HUVECs were treated with HMGB1 $(1 \mu \mathrm{g} / \mathrm{mL})$ and production of TNF- $\alpha$ (d) and IL-1 $\beta$ (e) in HUVECs was analyzed. Results are expressed as the mean \pm SEM of three independent experiments. ${ }^{*} p<0.05 v s$. HMGB1. 
might regulate the most important signals involved in induction of proinflammatory responses in human endothelial cells.

Protective Effect of Ginsenosides in CLP-induced Production of IL-6 and Septic Mortality. Sepsis, a systemic response to serious infection, has a poor prognosis when it is associated with organ dysfunction, hypoperfusion, or hypotension. $^{10,59}$ Production of IL-6 is required for pro-inflammatory responses and important markers of mortality. ${ }^{60}$ Based on our results, we hypothesized that treatment with ginsenosides would result in reduced production of IL-6 and decreased mortality in the CLP-induced sepsis mouse model. As shown in Figure 6(a), production of IL-6 in CLP-induced mice was reduced by treatment with each ginsenoside. This result was consistent with the previous finding that IL-6 levels were increased prior to death. ${ }^{61}$ To determine whether ginsenosides could protect mice from CLP-induced sepsis lethality, each ginsenoside was administered to mice after CLP. Twenty-four hours after the operation, animals manifested signs of sepsis, including shivering, bristled hair, and weakness. Administration of each ginsenoside $12 \mathrm{~h}$ after CLP did not prevent CLP-induced death (data not shown); therefore, each ginsenoside was administered two times (12 $\mathrm{h}$ and $50 \mathrm{~h}$ after CLP), resulting in an increase in the survival rate from $50 \%$ to $60 \%$ as determined by using Kaplan-Meier survival analysis $(p<0.0001$, Figs. 6(b) and (c)). However, no beneficial effect was observed at lower doses of each ginsenoside (data not shown). This marked survival benefit achieved by ginsenoside administration suggested that suppression of HMGB1 release and HMGB1-mediated inflammatory responses may provide a therapeutic strategy for the management of sepsis and septic shock.

(a)

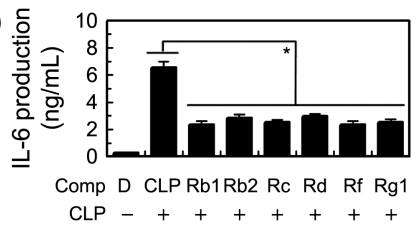

(b)

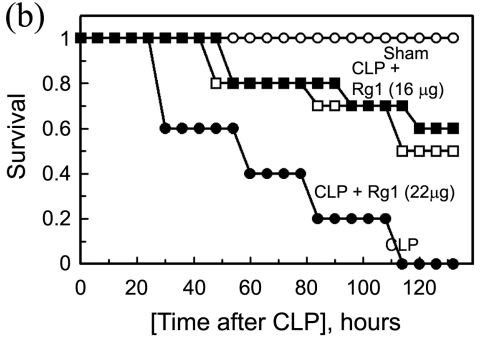

(c)

\begin{tabular}{lcc}
\hline & $66 \mathrm{~h}$ & $132 \mathrm{~h}$ \\
\hline $\mathrm{Rb} 1$ & $80 \%$ & $50 \%$ \\
$\mathrm{Rb} 2$ & $80 \%$ & $60 \%$ \\
$\mathrm{Rc}$ & $80 \%$ & $50 \%$ \\
$\mathrm{Rd}$ & $80 \%$ & $60 \%$ \\
$\mathrm{Rf}$ & $80 \%$ & $50 \%$ \\
$\mathrm{Rg} 1$ & $80 \%$ & $60 \%$ \\
\hline
\end{tabular}

Figure 6. Effects of ginsenosides on production of IL-6 and lethality after CLP. (a) Male C57BL/6 mice underwent CLP and were administered $10 \mu \mathrm{M}$ of each ginsenoside intravenously at 12 $\mathrm{h}$ and $50 \mathrm{~h}$ after CLP $(\mathrm{n}=5)$. Mice were euthanized $96 \mathrm{~h}$ after CLP. Serum IL-6 level was measured by using an ELISA. ( $b$ and $c$ ) Male C57BL/6 mice $(n=20)$ were administered $10 \mu \mathrm{M}$ of each ginsenoside intravenously at $12 \mathrm{~h}$ and $50 \mathrm{~h}$ after CLP. Animal survival was monitored every $6 \mathrm{~h}$ after CLP for $126 \mathrm{~h}$. Control CLP mice $(\bullet)$ and sham-operated mice $(O)$ were administered sterile saline $(\mathrm{n}=10)$. Kaplan-Meier survival analysis was used for determination of overall survival rates. ${ }^{*} p<0.05 v$. CLP.
Sepsis refers to a systemic inflammatory response syndrome resulting from a microbial infection. A wide array of pro-inflammatory cytokines including TNF- $\alpha$, IL- 1 , IFN- $\gamma$, and macrophage migration inhibitory factor, individually or in combination, contribute to the pathogenesis of lethal systemic inflammation. ${ }^{62}$ For instance, neutralizing antibodies against $\mathrm{TNF}^{63}$ reduced lethality in an animal model of endotoxemic/bacteremic shock. However, the early kinetics of systemic TNF accumulation make it difficult to target in the clinical setting, ${ }^{63}$ prompting the investigation of late proinflammatory mediators (such as HMGB1) as potential therapeutic targets for inflammatory diseases.

The prevailing theories of sepsis as a dysregulated systemic inflammatory response are supported by extensive studies using different animal models of sepsis including endotoxemia and peritonitis induced by CLP. ${ }^{64}$ In murine models of endotoxemia and sepsis, HMGB1 is first detectable in the circulation $8 \mathrm{~h}$ after onset, subsequently increasing to plateau levels from $16 \mathrm{~h}$ to $32 \mathrm{~h} .{ }^{65}$ The levels of circulating HMGB1 increase shortly before lethality from endotoxemia or sepsis, unlike those of TNF and other early proinflammatory cytokines. ${ }^{65}$ Therefore, in this study, each ginsenoside was administered $16 \mathrm{~h}$ after the inflammatory challenge.

\section{Conclusion}

In summary, our results demonstrated that ginsenosides inhibited both LPS- and CLP-mediated release of HMGB1, expression of HMGB1 receptors (TLR2, TLR4, and RAGE), and HMGB1-mediated barrier disruption through increasing barrier integrity and inhibiting CAM expression. In addition, ginsenosides reduced monocyte adhesion to endothelial monolayers and monocyte TEM. These barrier-protective effects of ginsenosides were confirmed in a mouse model, in which ginsenoside treatment resulted in a reduction of HMGB1-induced mortality. Our findings indicated that each of the tested ginsenosides may be a potential candidate for the treatment of severe vascular inflammatory diseases such as septic shock.

Acknowledgments. This study was supported by the National Research Foundation of Korea (NRF) funded by the Korean government [MSIP] (Grant Nos. NRF2012R1A4A1028835 and 2013-067053).

\section{References}

1. Martin, G. S.; Mannino, D. M.; Eaton, S.; Moss, M. N Engl. J. Med. 2003, 348, 1546.

2. Williams, S. C. Nat. Med. 2012, 18, 1001.

3. Wang, H.; Yang, H.; Tracey, K. J. J. Intern. Med. 2004, 255, 320.

4. Wang, H.; Zhu, S.; Zhou, R.; Li, W.; Sama, A. E. Expert. Rev. Mol. Med. 2008, 10, e32.

5. Takeuchi, O.; Akira, S. Int. Immunopharmacol. 2001, 1, 625.

6. Karlsson, S.; Pettila, V.; Tenhunen, J.; Laru-Sompa, R.; Hynninen, M.; Ruokonen, E. Intensive Care Med. 2008, 34, 1046.

7. Andersson, U.; Wang, H.; Palmblad, K.; Aveberger, A. C.; Bloom, O.; Erlandsson-Harris, H.; Janson, A.; Kokkola, R.; Zhang, M.; Yang, H.; Tracey, K. J. J. Exp. Med. 2000, 192, 565. 
8. Lotze, M. T.; Tracey, K. J. Nat. Rev. Immunol. 2005, 5, 331.

9. Yang, R.; Harada, T.; Mollen, K. P.; Prince, J. M.; Levy, R. M.; Englert, J. A.; Gallowitsch-Puerta, M.; Yang, L.; Yang, H.; Tracey, K. J.; Harbrecht, B. G.; Billiar, T. R.; Fink, M. P. Mol. Med. 2006, $12,105$.

10. Bae, J. S. Arch. Pharm. Res. 2012, 35, 1511.

11. Hori, O.; Brett, J.; Slattery, T.; Cao, R.; Zhang, J.; Chen, J. X.; Nagashima, M.; Lundh, E. R.; Vijay, S.; Nitecki, D.; et al. J. Biol. Chem. 1995, 270, 25752.

12. Park, J. S.; Svetkauskaite, D.; He, Q.; Kim, J. Y.; Strassheim, D.; Ishizaka, A.; Abraham, E. J. Biol. Chem. 2004, 279, 7370.

13. Andersson, U.; Tracey, K. J. Annu. Rev. Immunol. 2011, 29, 139.

14. Tung, N. H.; Song, G. Y.; Park, Y. J.; Kim, Y. H. Chem. Pharm. Bull. (Tokyo) 2009, 57, 1412.

15. Cui, J. F.; Garle, M.; Lund, E.; Bjorkhem, I.; Eneroth, P. Anal. Biochem. 1993, 210, 411.

16. Chan, R. Y.; Chen, W. F.; Dong, A.; Guo, D.; Wong, M. S. J. Clin. Endocrinol. Metab. 2002, 87, 3691.

17. Attele, A. S.; Wu, J. A.; Yuan, C. S. Biochem. Pharmacol. 1999, $58,1685$.

18. Morisaki, N.; Watanabe, S.; Tezuka, M.; Zenibayashi, M.; Shiina, R.; Koyama, N.; Kanzaki, T.; Saito, Y. Br. J. Pharmacol. 1995, 115, 1188.

19. Lee, Y. J.; Jin, Y. R.; Lim, W. C.; Park, W. K.; Cho, J. Y.; Jang, S.; Lee, S. K. Arch. Pharm. Res. 2003, 26, 58.

20. Korivi, M.; Hou, C. W.; Huang, C. Y.; Lee, S. D.; Hsu, M. F.; Yu, S. H.; Chen, C. Y.; Liu, Y. Y.; Kuo, C. H. Evid Based Complement. Alternat. Med. 2012, 2012, 932165.

21. Zhang, G.; Liu, A.; Zhou, Y.; San, X.; Jin, T.; Jin, Y. J. Ethnopharmacol. 2008, 115, 441.

22. Angus, D. C.; Yang, L.; Kong, L.; Kellum, J. A.; Delude, R. L.; Tracey, K. J.; Weissfeld, L. Crit. Care. Med. 2007, 35, 1061.

23. Chen, G.; Ward, M. F.; Sama, A. E.; Wang, H. J. Interferon Cytokine Res. 2004, 24, 329.

24. Yang, H.; Tracey, K. J. Biochim. Biophys. Acta 2010, 1799, 149.

25. Yang, H.; Wang, H.; Czura, C. J.; Tracey, K. J. J. Leukoc. Biol. 2005, 78, 1 .

26. Bae, J. S.; Rezaie, A. R. Thromb. Haemost. 2008, 100, 101.

27. Lee, W.; Yang, E. J.; Ku, S. K.; Song, K. S.; Bae, J. S. BMB Rep. 2012, 45, 390 .

28. Kim, T. H.; Bae, J. S. Food Chem. Toxicol. 2010, 48, 1682.

29. Lee, W.; Kim, T. H.; Ku, S. K.; Min, K. J.; Lee, H. S.; Kwon, T. K.; Bae, J. S. Toxicol. Appl. Pharmacol. 2012, 262, 91.

30. Che, W.; Lerner-Marmarosh, N.; Huang, Q.; Osawa, M.; Ohta, S.; Yoshizumi, M.; Glassman, M.; Lee, J. D.; Yan, C.; Berk, B. C.; Abe, J. Circ. Res. 2002, 90, 1222.

31. Kim, T. H.; Ku, S. K.; Lee, I. C.; Bae, J. S. BMB Rep. 2012, 45, 200.

32. Bae, J. S.; Rezaie, A. R. Blood 2011, 118, 3952.

33. Bae, J. S.; Lee, W.; Rezaie, A. R. J. Thromb. Haemost. 2012.

34. Lee, J. D.; Huh, J. E.; Jeon, G.; Yang, H. R.; Woo, H. S.; Choi, D. Y.; Park, D. S. Int. Immunopharmacol. 2009, 9, 268.

35. Valerio, D. A.; Cunha, T. M.; Arakawa, N. S.; Lemos, H. P.; Da Costa, F. B.; Parada, C. A.; Ferreira, S. H.; Cunha, F. Q.; Verri, W. A., Jr. Eur. J. Pharmacol. 2007, 562, 155.

36. Akeson, A. L.; Woods, C. W. J. Immunol. Methods 1993, 163, 181 .

37. Wang, H.; Liao, H.; Ochani, M.; Justiniani, M.; Lin, X.; Yang, L.; Al-Abed, Y.; Metz, C.; Miller, E. J.; Tracey, K. J.; Ulloa, L. Nat. Med. 2004, 10, 1216.

38. El Gazzar, M. Inflamm. Res. 2007, 56, 162.
39. Mullins, G. E.; Sunden-Cullberg, J.; Johansson, A. S.; Rouhiainen, A.; Erlandsson-Harris, H.; Yang, H.; Tracey, K. J.; Rauvala, H.; Palmblad, J.; Andersson, J.; Treutiger, C. J. Scand J. Immunol. 2004, 60, 566.

40. Buras, J. A.; Holzmann, B.; Sitkovsky, M. Nat. Rev. Drug. Discov. 2005, 4, 854 .

41. Sama, A. E.; D'Amore, J.; Ward, M. F.; Chen, G.; Wang, H. Acad. Emerg. Med. 2004, 11, 867.

42. Berman, R. S.; Frew, J. D.; Martin, W. Br. J. Pharmacol. 1993, $110,1282$.

43. Goldblum, S. E.; Ding, X.; Brann, T. W.; Campbell-Washington, J. J. Cell Physiol. 1993, 157, 13.

44. Wolfson, R. K.; Chiang, E. T.; Garcia, J. G. Microvasc. Res. 2011, $81,189$.

45. Qin, Y. H.; Dai, S. M.; Tang, G. S.; Zhang, J.; Ren, D.; Wang, Z. W.; Shen, Q. J. Immunol. 2009, 183, 6244.

46. Sun, C.; Liang, C.; Ren, Y.; Zhen, Y.; He, Z.; Wang, H.; Tan, H.; Pan, X.; Wu, Z. Basic Res. Cardiol. 2009, 104, 42.

47. Schnittler, H. J.; Schneider, S. W.; Raifer, H.; Luo, F.; Dieterich, P.; Just, I.; Aktories, K. Pflugers Arch. 2001, 442, 675.

48. Friedl, J.; Puhlmann, M.; Bartlett, D. L.; Libutti, S. K.; Turner, E. N.; Gnant, M. F.; Alexander, H. R. Blood 2002, 100, 1334.

49. Petrache, I.; Birukova, A.; Ramirez, S. I.; Garcia, J. G.; Verin, A. D. Am J. Respir Cell Mol. Biol. 2003, 28, 574.

50. Hansson, G. K.; Libby, P. Nat. Rev. Immunol. 2006, 6, 508.

51. Kawahara, K.; Hashiguchi, T.; Kikuchi, K.; Tancharoen, S.; Miura, N.; Ito, T.; Oyama, Y.; Nawa, Y.; Biswas, K. K.; Meng, X.; Morimoto, Y.; Shrestha, B.; Sameshima, H.; Maruyama, I. Int. J. Mol. Med. 2008, 22, 639.

52. Dagia, N. M.; Agarwal, G.; Kamath, D. V.; Chetrapal-Kunwar, A.; Gupte, R. D.; Jadhav, M. G.; Dadarkar, S. S.; Trivedi, J.; KulkarniAlmeida, A. A.; Kharas, F.; Fonseca, L. C.; Kumar, S.; Bhonde, M. R. Am J. Physiol. Cell Physiol. 2010, 298, C929.

53. Wang, F. P.; Li, L.; Li, J.; Wang, J. Y.; Wang, L. Y.; Jiang, W. PLoS One 2013, 8, e64373.

54. Lockyer, J. M.; Colladay, J. S.; Alperin-Lea, W. L.; Hammond, T.; Buda, A. J. Circ. Res. 1998, 82, 314.

55. Marui, N.; Offermann, M. K.; Swerlick, R.; Kunsch, C.; Rosen, C. A.; Ahmad, M.; Alexander, R. W.; Medford, R. M. J. Clin. Invest. 1993, 92, 1866 .

56. Rose, B. A.; Force, T.; Wang, Y. Physiol. Rev. 2010, 90, 1507.

57. Park, J. S.; Gamboni-Robertson, F.; He, Q.; Svetkauskaite, D.; Kim, J. Y.; Strassheim, D.; Sohn, J. W.; Yamada, S.; Maruyama, I.; Banerjee, A.; Ishizaka, A.; Abraham, E. Am J. Physiol. Cell Physiol. 2006, 290, C917.

58. Palumbo, R.; Galvez, B. G.; Pusterla, T.; De Marchis, F.; Cossu, G.; Marcu, K. B.; Bianchi, M. E. J. Cell Biol. 2007, 179, 33.

59. Cohen, J. Nature 2002, 420, 885.

60. Teiten, M. H.; Eifes, S.; Dicato, M.; Diederich, M. Toxins (Basel) 2010, 2, 128.

61. Xiao, H.; Siddiqui, J.; Remick, D. G. Infect. Immun. 2006, 74, 5227.

62. Bhatia, M.; He, M.; Zhang, H.; Moochhala, S. Front Biosci. 2009, 14,4703 .

63. Tracey, K. J.; Fong, Y.; Hesse, D. G.; Manogue, K. R.; Lee, A. T.; Kuo, G. C.; Lowry, S. F.; Cerami, A. Nature 1987, 330, 662.

64. Wichterman, K. A.; Baue, A. E.; Chaudry, I. H. J. Surg. Res. 1980, $29,189$.

65. Wang, H.; Yang, H.; Czura, C. J.; Sama, A. E.; Tracey, K. J. Am J. Respir Crit. Care Med. 2001, 164, 1768. 